\title{
Designing and fabrication of an installation PV solar modules tilting platform
}

\author{
Emmanuel Olusegun Ogundimu ${ }^{{ }^{*}}$, Esther Akinlabi ${ }^{1}$, Chigbo Mgbemene $^{2}$, Ifeanyi Jacobs ${ }^{2}$ \\ ${ }^{1}$ Department of Mechanical Engineering, University of Johannesburg, Johannesburg, Gauteng, South Africa \\ ${ }^{2}$ Department of Mechanical Engineering, University of Nigeria, Nsukka, Enugu, Nigeria

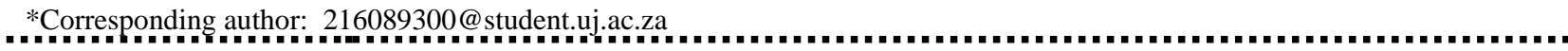

Received Aug. 6, 2021

Revised Oct. 23, 2021

Accepted Nov. 15, 2021

\begin{abstract}
The optimum tilt-angle of a fixed photovoltaic solar panel is very important during the installation, in order to best exploit the accessible output power efficiency of the panel. The output power effectiveness of a PV solar collector is profoundly affected by its tilt-angle to the horizontal and its orientation. This is because of the detail that the sun's angle varies at every point of time and location. The solar photovoltaic tilting platform plays a dynamic role in the installation of the solar photovoltaic panel. From one perspective, it protects the solar panel from mechanical pressures that can arise from the wind movement and the hand; it provides means of adjustment for the solar panel. The proposed solar photovoltaic tilting platform was designed for an adjustable angle capacity oscillating from $0^{0}$ to $40^{\circ}$; the materials used for the construction of the tilting platform are capable to withstand a load of $45 \mathrm{~kg}$ and resist a temperature of $-50^{\circ} \mathrm{F}$ to $150^{\circ} \mathrm{F}$ under a maximum wind force of $3.78 \mathrm{~N}$. The numerous mechanisms of the PV tilting platform prototype were tested, the stability, strength, easy titling, and overall performance of the PV tilting platform were declared as satisfactory.
\end{abstract}

(C) The Author 2022. Published by ARDA

Keywords: Design; Photovoltaic; Platform; Tilt-angle

\section{Introduction}

Renewable power source assets appear to be the standout amongst the best and most productive answers for the global energy problem [1]. The impacts of environmental change have turned into a serious reality of the $21^{\text {st }}$ century. There is an urgent consideration of the renewable power, as it is increasingly replacing the traditional power sources in homes and businesses, because of its free sources. The solar photovoltaic tilting platform plays a dynamic role in the installation of the solar photovoltaic panel. From one perspective, it protects the solar panel from mechanical pressures that can arise from the wind movement and the hand. This includes mounting the single solar module or a solar array at the appropriate tilt angle. The kind of solar panel that best fits a private house is poly-crystalline in light of the fact that it is the reasonable per unit area [2-4]. This is genuine on the grounds that the unit area is anything but a huge factor for the plan. For this application, the primary rules for the solar panel are spot of assembling, wattage, size, outline material, and effectiveness. The wattage is another significant factor since it educates how much force will be gotten. The elements of the solar panel are required with the goal that the size of the sections can be resolved. The casing material is a vital determinant of the material utilized for the mounting framework to shun corrosion. The proficiency is significant on the grounds that it controls how much force is created relying upon solar power. When a solar panel is picked the plan can be finished and estimations for wind loads, tipping analysis and stress analysis can be completed [5].

Rooftops are perfect spaces for lesser-scale solar PV set-ups because there are unoccupied large areas; and also, because rooftops receive copious solar emissions from the sun. This is mostly done on the building's roof, as shown in Fig. 1.

This work is licensed under a Creative Commons Attribution License (https://creativecommons.org/licenses/by/4.0/) that allows others to share and adapt the material for any purpose (even commercially), in any medium with an acknowledgement of the work's authorship and initial publication in this journal. 


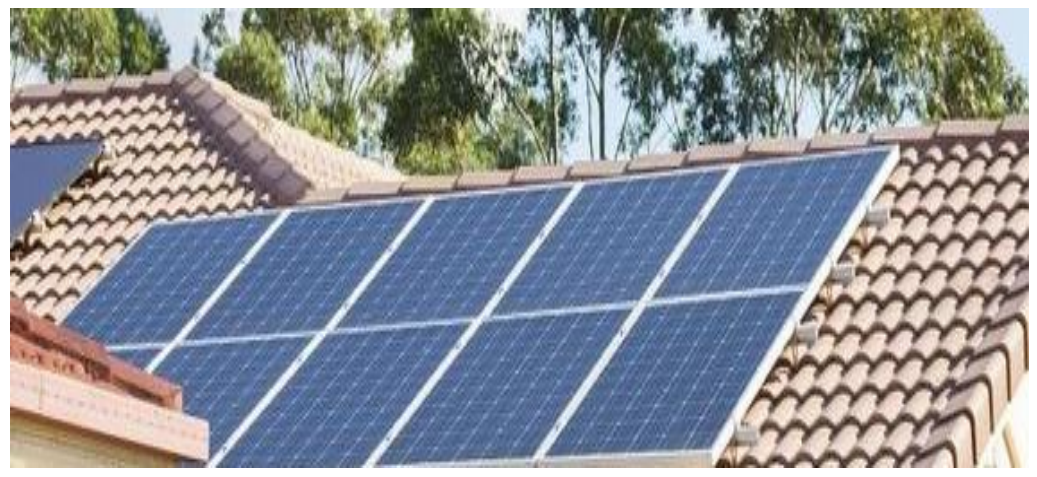

Figure 1. Roof-installed PV solar panels

Rooftop solar arrays are less expensive to install and more convenient to use. The rooftop mount framework incorporates a bunch of bases which are attached to the rooftop surface. A bunch of rails are dashed to the feet. Solar modules are mounted straightforwardly to the rails with bolt-on brace connectors. 25-millimetre spacers are introduced between the sides edges of modules to hold them set up. End clips secure the modules to the rails. The actual cluster is mounted roughly 102 to 152 millimetre off the outside of the rooftop to permit admittance to pull and interface the photovoltaic panel links, and allows air flow around the system to limit overheating of the solar modules. Lower material costs differentiated with other mounting frameworks is a benefit of rooftop mount frameworks, and limited admittance by unqualified professional. But they are constrained by the features and properties of the roof on which they are mounted. If the rooftops are at a suitable angle; and they have obstructions, like skylights or chimneys, or it does not face southwards, then the array of the solar PV would be less productive [7-8]. A sole panel or a minor array of photovoltaic panel can be installed on a casing also, joined to a pole. A sole panel can be mounted on a side-mount outline connected to the side of a pole or on the highest point of the post. The pole of about 75 to 100 millimetre in diameter and high 4 to 6 metres are commonly used [9].

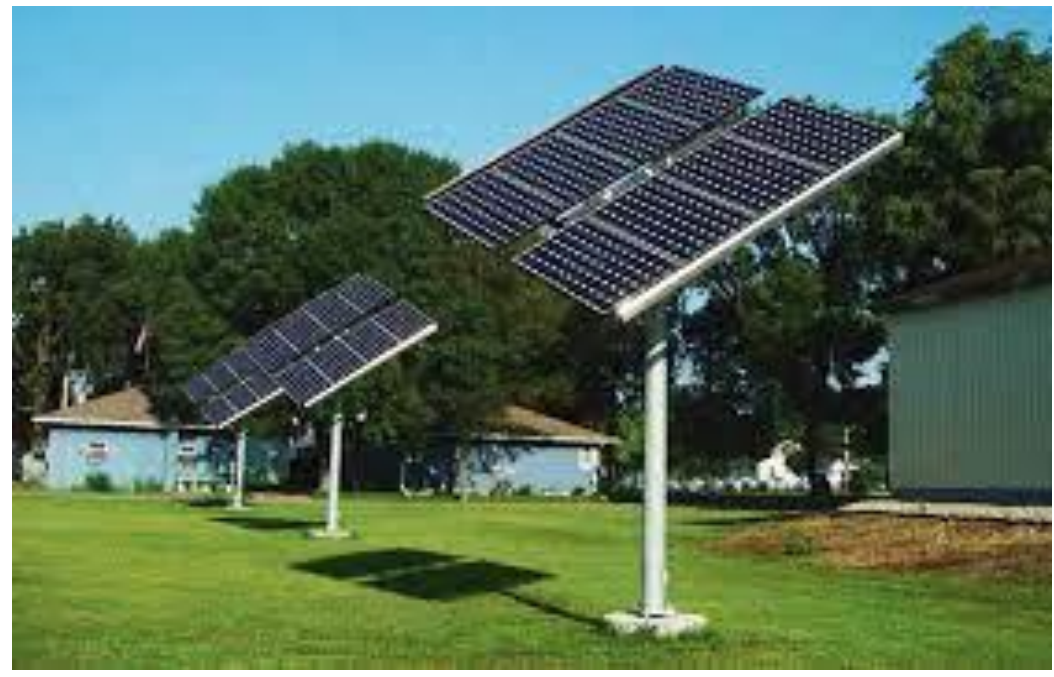

Figure 2. Pole installed solar modules [10]

While pole mounting solar panels can expand openness to daylight, it requires a huge part of land to be committed to the solar establishment. Consequently, solar panel pole mounting will in general be restricted to business or agrarian establishments, or on huge private properties [10].

Ground mounts, as shown in Fig. 2., are using metallic mounting on the ground to hold solar PV modules up at a secure angle. Some typical ground-fixed solar PV modules systems can be attuned a few times a year to account for the periodic shifts of the sun. Also, ground-fixed solar PV modules systems are stress-free once they are installed, because they can be positioned on open land. Drilling into the rooftop is not required and the bracings used in standard ground-mounted structures are not heavy compared to the rooftop; and they are easy to remove. Moreover, a ground-mounted solar panel system could be more effective per solar module compared to a rooftop solar array; since they are not reliant on the angle of the rooftop, and ground-fixed solar PV modules can be set at the perfect tilt-angle to enhance power generation. 


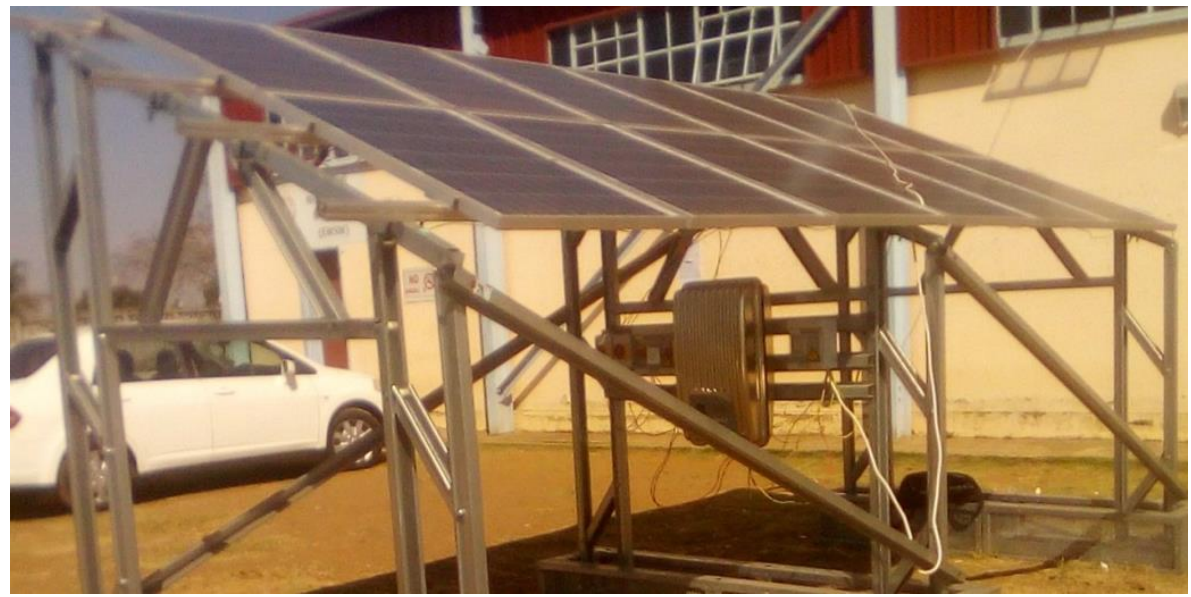

Figure 3. Ground- mounted solar PV modules at Capricorn TVET College

The angle of the sun varies throughout the year; so, a fixed tilt-angle cannot be used throughout the year. A fixed tilt panel cannot harvest the maximum power output from the sunlight year-round. The unconventional technique is to increase the quantity of generated electric power in solar PV modules by setting them at an optimum tilt-angle monthly, or periodically. The large measure of previous work done in this area focused on the month-to-month tilt-angle of the solar PV modules collectors; and the results verified that the tilt-angle depends on the angle of latitude of the locality. This project suggests the designing and construction of solar photovoltaic tilting platform.

\section{Methodology}

This chapter aims to present the design, calculation and fabrication processes of the solar photovoltaic tilting platform and the installation process at the test ring.

\subsection{Designing of installations PV solar panel tilting platform}

The solar photovoltaic tilting platform plays a dynamic role in the installation of the solar photovoltaic panel. From one perspective, it protects the solar panel from mechanical pressures that can arise from the wind movement and the hand; it provides means of adjustment for the solar panel. For the purpose of this research, the following design specifications will be considered:

- It should have an adjustable angle capacity oscillating from $0^{\circ}$ to $40^{\circ}$;

- It should be able to function in any part of the Nigerian territories;

- It should be securely safeguarded to the ground;

- The solar PV modules should be steadily fixed firmly on it;

- The materials used for the construction of the tilting platform should able to resist a temperature of $-50^{\circ} \mathrm{F}$ to $150^{\circ} \mathrm{F}$.

- The materials used for the construction of the tilting platform should be corrosion-resistant.

- The tilting platform should be easy and cost-efficient in its construction

- It must be manufactured locally;

- The total weight of the package should be less than $45 \mathrm{~kg}$.

- The manual must be included; and it must have easy-to-understand directions.

- It must be simple to be assembled by anyone.

Fig. 4 shows the 3D first-angle and third-angle isometrics of the proposed solar photovoltaic tilting platform.

Fig. 5 displays the assembly drawing of the solar photovoltaic tilting platform, indicating the different parts that make it up. Platform C carries the PV; while part B is the end-holder for the PV. The end-holders prevent the $\mathrm{PV}$ from tilting over the end of $\mathrm{C}$; and they prevent it from sliding down. Part D lifts platform $\mathrm{C}$ to the required angle of $\theta$. 

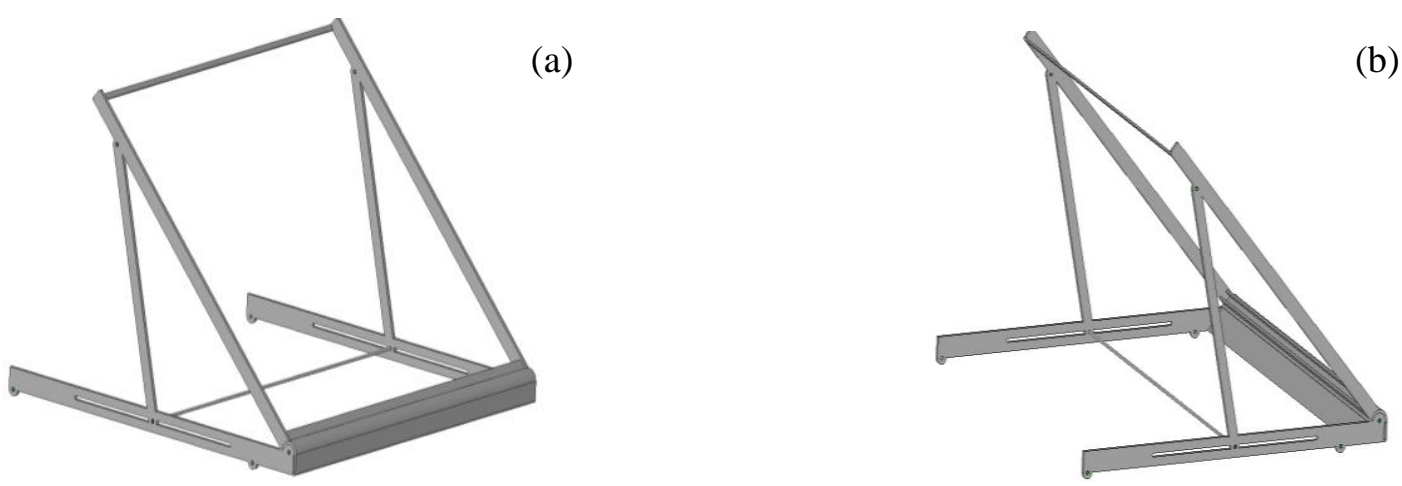

Figure 4. 3D first-angle (a) and third angle (b) isometric model of the proposed solar photovoltaic tilting platform

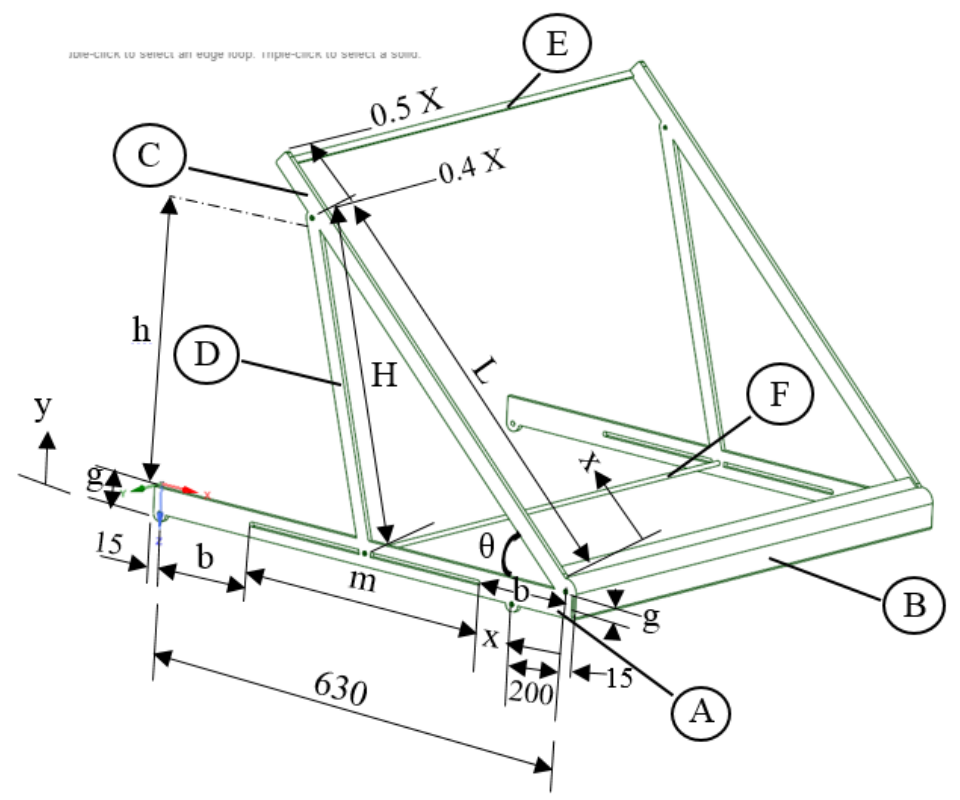

Figure 5. The assembly drawing of the proposed solar photovoltaic tilting platform

Part D connects parts C and A. Part A is the attaching framework to the existing test bed's platform. It carries the whole solar photovoltaic tilting platform. Part A also provides the slot, in which one end of part D moves. One end of part $\mathrm{D}$ is attached to $\mathrm{C}$; while the other slots into $\mathrm{A}$. The slotting end has a lock-nut attached to it, in order to fix it at the stipulated $\theta$ angle.

The lock nut holds parts A, D and F together. Part F is a circular shaft with bearings at the two ends seriatim on rails on part A. One end of part $\mathrm{A}$ has a bearing in it, on which part $\mathrm{C}$ swivels.

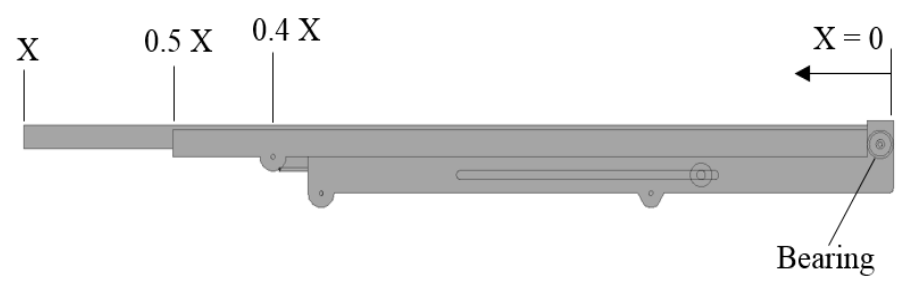

Figure 6. The side view proposed solar photovoltaic tilting platform at an angle $\theta=0^{\circ}$

Fig. 6 indicates the side view of the PVTP at $\theta=0^{\circ}$; while $X$ indicates the length of the PV module. The length of part $\mathrm{C}$ is equal to $0.5 \mathrm{X}$; while the position of the attachment of $\mathrm{D}$ to $\mathrm{C}$ is at $0.4 \mathrm{X}$. This figure also shows the location of the bearing of part A. Fig. 7 shows the notations for the design analysis: 


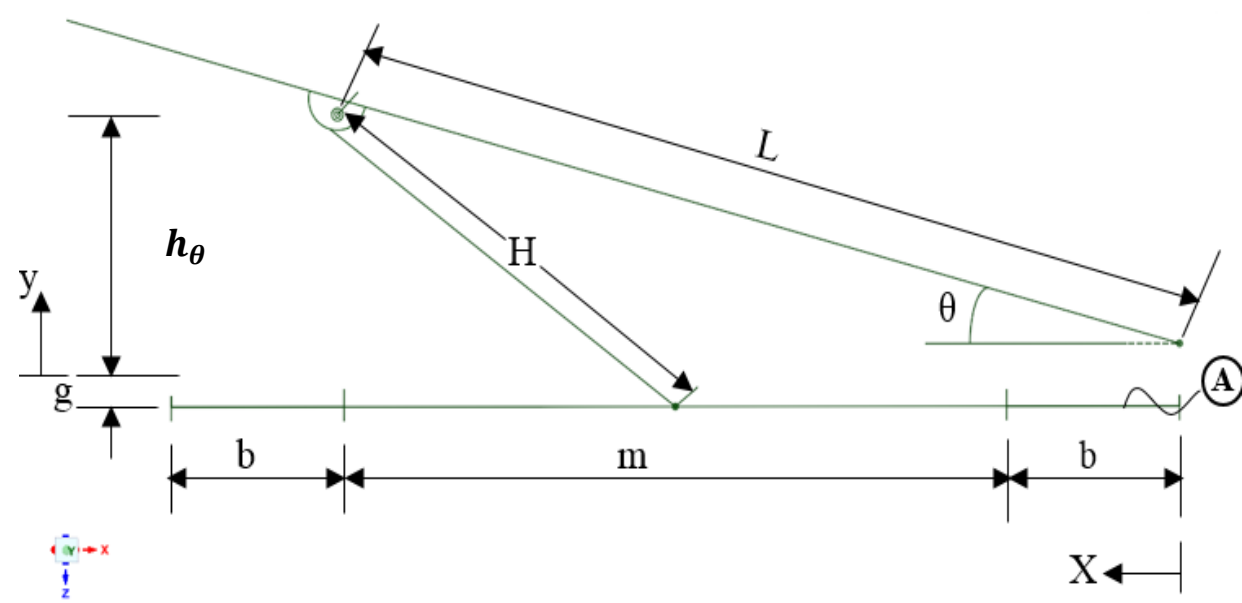

Figure 7. The notation analysis for the design

where,

$\Theta=$ tilt angle

$b=$ space between slot $\mathrm{m}$ and ends of bar A

$m=$ length of the slot

$g=$ height of centrelines of slot and bearing in bar

$h_{\theta}=$ height to which the platform $\mathrm{C}$ is raised, depending on $\theta$

$H=$ length of $\mathrm{D}$ link

$L=$ Distance of the position of $\mathrm{D}$ link attachment pivot from $\mathrm{X}=0$

\subsection{The kinematic study of the PVTP}

The study started with the choice of some certain parameters, which would affect the performance of the system. The parameters, here are $\theta$ and g, chosen as $20 \mathrm{~mm}$ as the minimum, and $\theta=45^{\circ}$ as the maximum. This is such that part $\mathrm{C}$ will not encroach into bar $\mathrm{A}$. Thus, this is the minimum gap between part $\mathrm{C}$ and bar $\mathrm{A}$. With that, the boundary conditions for the movement of part $\mathrm{C}$ become:

At $\theta=45^{\circ}$ This gives the maximum height of $h_{\theta}$ )

$$
\begin{aligned}
& m_{\theta}=h_{\theta \max }-b \ldots \ldots \ldots \ldots \ldots \ldots \ldots \\
& \text { at } \theta=0^{\circ}, m_{\theta}=0 \ldots \ldots \ldots \ldots \ldots \ldots \\
& \text { At } \theta=45^{\circ}, y=|g|+h_{\theta \max } \\
& Y=H=|g|+L \sin 45 \ldots \ldots \ldots
\end{aligned}
$$

(m) represents the linear movement of the mobile end of the representing D link.

Note: in the part (D) link, one end makes an angular motion; while the other end makes a linear motion; and the position of $\mathrm{m}$ at every $(\theta)$ relative to $\left(h_{\theta}\right)$ was found to be exponential in nature. Hence, although $\mathrm{m}$ moves in a linear path, the position at the stipulated angle of $(\theta)$ varies exponentially to the height $\left(h_{\theta}\right)$ and $(\theta)$. The following relationships guiding the positions of points and lengths of links were developed, based on the foregoing logic. The position of $(\mathrm{m})$ at every angle $(\theta)$ is represented by $\left(m_{\theta}\right)$.

$$
\begin{aligned}
& L=0.4 X \text {. } \\
& h_{\theta}=\operatorname{Lsin} \theta \\
& h_{\theta \max }=\mathrm{L} \sin 45 \\
& m_{\theta}=\left[e^{\left(\frac{\frac{y}{s c a l e}-N}{13.8}\right)}\right] \text { scale } \\
& X_{\text {max }}=m+2 b \\
& \mathrm{~b}=\mid-g+\frac{L}{35} * \text { scale } \mid \text {. }
\end{aligned}
$$


Equations (1) to (10) are the general relationships, which can be applied to the different values of X. In the application for designing, $\mathrm{g}$ and $\mathrm{X}$ are chosen and plugged into the relevant equations. Also chosen, is the scale of the drawing size to which it relates, ' $m$ '.

The force analysis was done, based on the weight of each module. Each module weighed $50 \mathrm{Kg}$, which is approximately $500 \mathrm{~N}$. To determine the sizes of the angle bars made of rolled mild steel, Fig. 3 was redrawn and then simplified, as shown in Fig. 8 (a) and Fig. 8 (b), respectively. Fig. 8 (b) depicts the PVTP as a simply supported beam supporting a point load $\mathrm{P}$.

The angle bars are made of annealed rolled steel with a yield stress of $300 \mathrm{MPa}$ and $\mathrm{E}=200 \mathrm{GNm}^{-2}$. We want to determine the reactions at the support of the bearing and the minimum allowable cross-sectional area of part A to support the load of $500 \mathrm{~N}$.

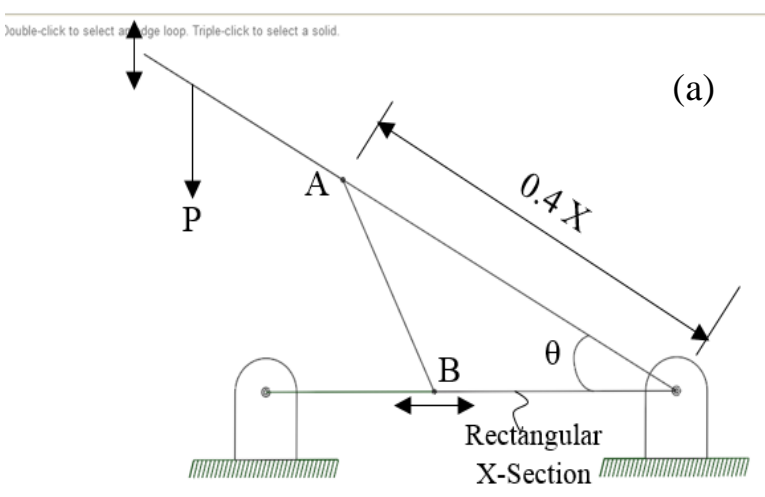

(b)

Figure 8. (a) Redrawn diagram of the PVTP (b) the free body diagram of the PVTP

Fig. 9 depicts the cross-sectional area under consideration as $a^{*} b$. considering it as a beam under point load, there is bound to be a deflection of the beam due to the load.

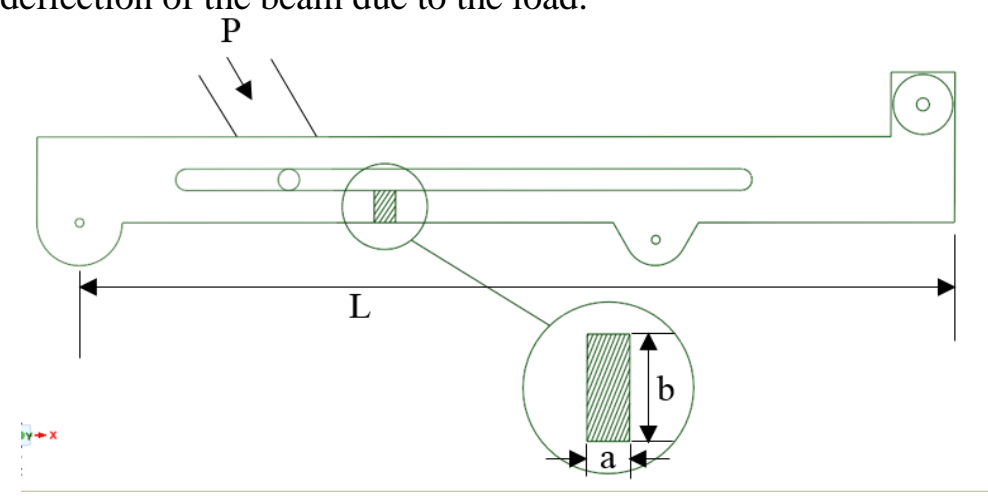

Figure 9. Cross sectional area under consideration

Assuming a deflection, $\Delta$ of $0.1 \mathrm{~mm}$ and using the equation:

$$
\Delta=\frac{P L}{A E}
$$

where,

$\mathrm{L}$ is the length of the bar $=0.4 \mathrm{X}$

$0.4 \mathrm{X}=400 \mathrm{~mm}$

$\mathrm{A}=$ Cross-sectional are $\mathrm{a}=\mathrm{a} * \mathrm{~b}$

$$
A=\frac{P L}{\Delta E}
$$

$\mathrm{A}=\frac{500 * 400}{0.1 * 200 * 10^{3}}=10 \mathrm{~mm}^{2}$ 
This translates to $\mathrm{a}=2.5 \mathrm{~mm}, \mathrm{~b}=4 \mathrm{~mm}$. This is the minimum allowable cross section to support a $500 \mathrm{~N}$ load. The reactions are determined thus, let

$$
\begin{aligned}
& \mathrm{L} 1=\frac{L_{2}}{3} \\
& \text { Now } \sum F_{v}=0, R_{1+} R_{2}=\mathrm{P} \text {. } \\
& \sum M_{2}=0, \mathrm{P} L_{2}=R_{1}\left(L_{1}+L_{2}\right) \\
& \mathrm{P} L_{2}=R_{1}\left(\frac{L_{2}}{3}+L_{2}\right) \\
& R_{1}=\frac{3 P}{4} \text {. } \\
& R_{1}=\frac{3 * 500}{4}=375 \mathrm{~N}
\end{aligned}
$$

Substituting for $R_{1}$ in equation (17)

$$
R_{1}=(500-375)=125 \mathrm{~N}
$$

The results are in agreement with the expected values; because the actual panel has more than half of its length extending beyond part B, as shown in Fig. 8 (a). Consequently, more of the weight of the panel will be borne by $R_{1}$. Since this is logical, the values of the computed cross-sectional area ' $\mathrm{a}$ ' and ' $\mathrm{b}$ ' are acceptable. The available angle bars in the market come in the size of $2.5 \mathrm{~mm} * 50 \mathrm{~mm}$. Thus, it was settled for. The actual value of ' $b$ ' in the design, was however, chosen as $10 \mathrm{~mm}$, in order to allow for the incorporation of a roller bearing rail to the bar. The next sections to be designed for thickness are part C. A free body diagram of part $\mathrm{C}$ is, as shown in Fig. 10.
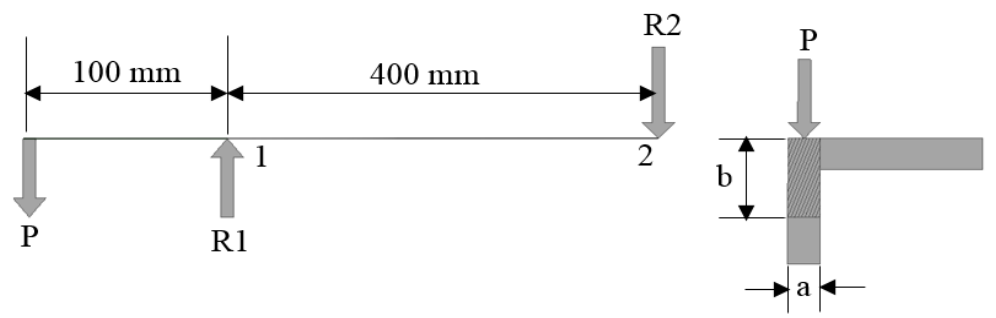

Figure 10. Free body diagram of part C

Now $\sum F_{v}=0$

$$
R_{1=} R_{2}+\mathrm{P}
$$

$\sum M_{2}=0$,

$$
500 \mathrm{P}=400 R_{1}
$$

$$
\begin{aligned}
& R_{1}=\frac{500 * 500}{400}=625 \mathrm{~N} \\
& R_{2}=R_{1}-P=(625-500)=125 \mathrm{~N}
\end{aligned}
$$

We expect more deflection under this load, so let us assume a deflection of $0.2 \mathrm{~mm}$. So that

$A=\frac{500 * 500}{0.2 * 200 * 10^{3}}=6.25 \mathrm{~mm}^{2}$

This implies that $\mathrm{a} * \mathrm{~b}=6.25 \mathrm{~mm}^{2}$ which translates to $1.5 \mathrm{~mm} * 4.2 \mathrm{~mm}$. An angle bar of $1.5 \mathrm{~mm} * 38 \mathrm{~mm}$ was available, thus it was settled for.

Having obtained the minimum dimensions, the parts were dimensioned by using equations $1-10$. The dimensions of the platform were then determined. Appropriate bolt sizes were then selected for joining the parts. The detailed drawing of this proposed tilting platform based on the dimensions obtained from equation 1 to 19 is shown in Fig. 11. 


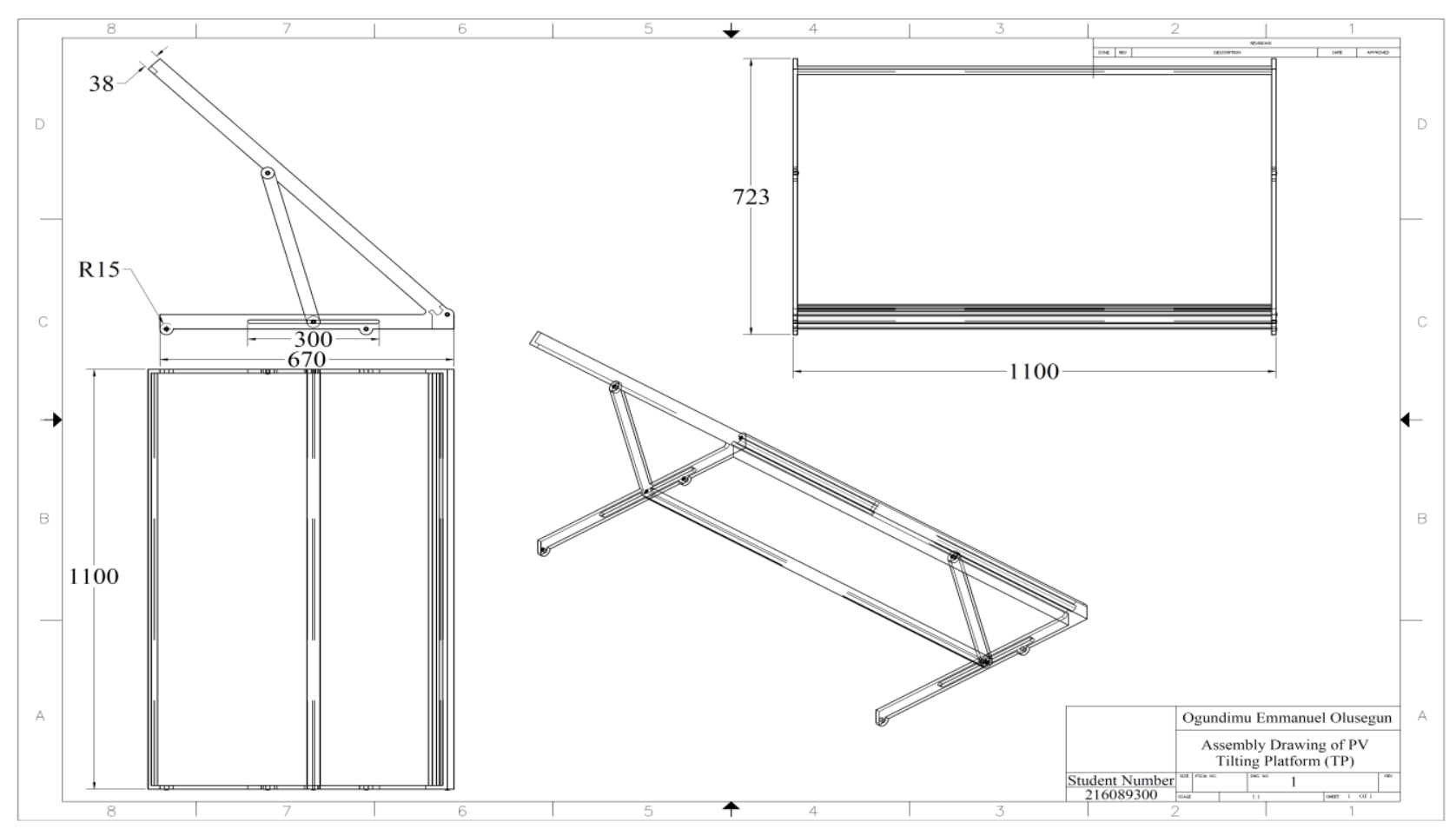

Figure 11: Assembly drawing of the proposed PV tilting platform

\subsection{Wind loads}

There has been several schoolwork on the impacts of wind loads on installed solar modules. In this design, the maximum wind load exerted on a single solar module will be determined. Wind Load Calculations, is used to estimate the perpendicular force applied on the frame of the solar module installed on the ground [11-12].

$$
F=\rho * v^{2} * S * \sin ^{2} \vartheta
$$

where,

$$
\begin{aligned}
& \mathrm{F}=\text { wind load } \\
& \rho=\text { the air density }\left(\mathrm{kg} / \mathrm{m}^{3}\right) \\
& v=\text { the wind speed }(\mathrm{m} / \mathrm{s}) \\
& \mathrm{S}=\text { the surface area of the photovoltaic panel }\left(\mathrm{m}^{2}\right) \\
& \vartheta=\text { the angle of tilt of photovoltaic panel. }
\end{aligned}
$$

In this calculation, an air density at 1 atmospheric pressure and average temperature of $29^{\circ} \mathrm{C}$, the wind speed of $2.2 \mathrm{~m} / \mathrm{s}$ and air density of $1.11 \mathrm{~kg} / \mathrm{m}^{3}$ are generated using an online air - density calculator [13 ]. The surface area of the 250 watts solar panel of dimension 1640 by $1002 \mathrm{~mm}$ is $1.703 \mathrm{~m}^{2}$ and the PV tilting platform will be design to tilt from angle 0 to 40 degrees, so the maximum tilting angle of 40 degrees will be used in the wind load calculations. The resulting wind load by applying equation (20) is $3.78 \mathrm{~N}$, which will be the highest wind load that the design should withstand.

\section{Fabrication of PV tilting platform prototype}

During fabrication, some slight modifications were made, based on the behaviors of the materials when worked and when in operation. For example, the effect of machining, welding, bending, installation and friction had to be considered. These necessitated slight changes in the dimensions; but none of them went below the designed dimensions. Increments to the dimension were rather made, where necessary. All the parts were fabricated, as shown in Fig. 12 (a). After which, the fabricated parts were bolted together, using M10 bolts and nuts and the fabricated parts of the solar photovoltaic tilting platform were sub-assembled as shown in Fig. 12 (b-d) The 
completed assembled tilting platforms prototype are shown in Fig. 12 (e). There are four pieces of solar photovoltaic tilting platform in the final set-up, but only three were used for testing and the validation of the present work as indicated in Fig. 12 (f).
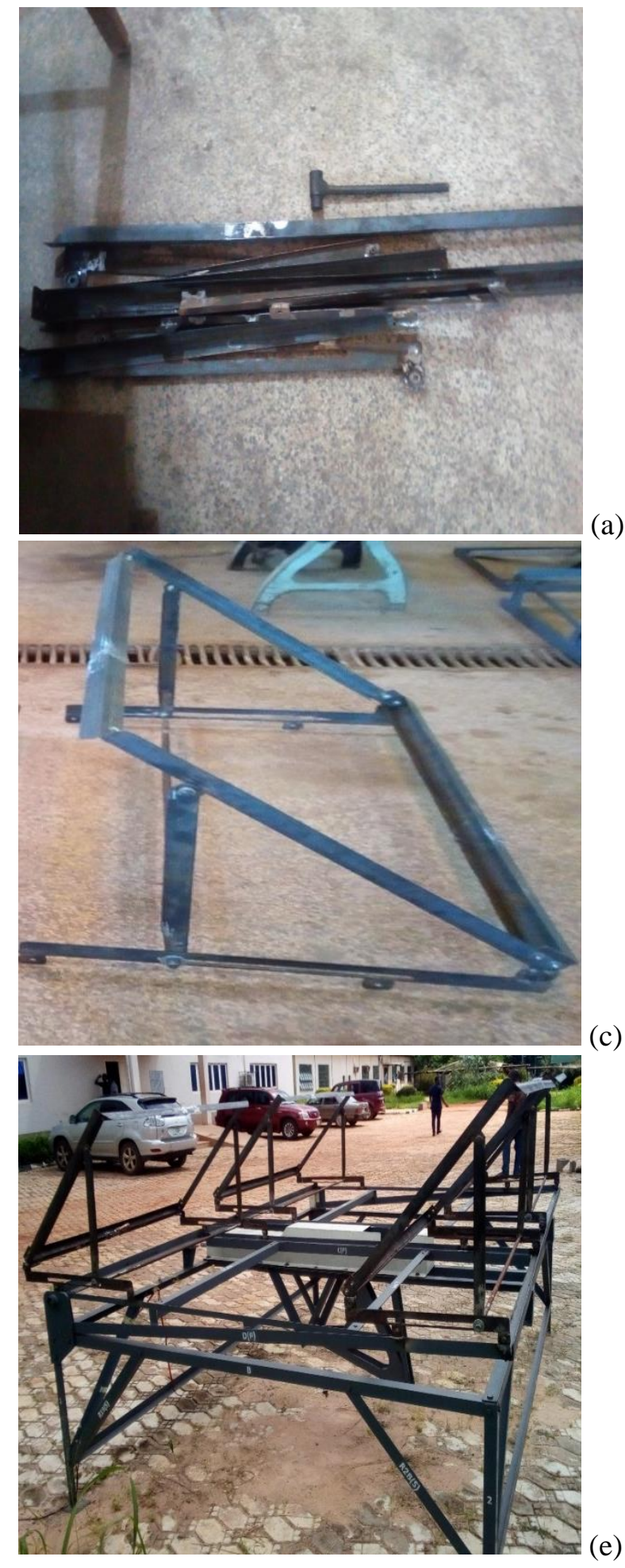

Figure 12. (a-f) The fully fabricated solar photovoltaic tilting platform prototype

\section{Testing and validation of the designed PV tilting platform}

Testing and validation of the designed device is a dynamic method in the development and comprehension of any design, be it software-based, or hardware-based. The numerous mechanisms should be tested, to certify that all 
the mechanisms on the project are certified satisfactorily. The first stage of this process was to test the performance of the PV tilting platform prototype. Three of the 250 watts of each photovoltaic solar panels were placed on the PV tilting platform; and the PV tilting platform was made to tilt from angle 0 to 40 degrees, as shown in Fig. 13 (a). The stability, strength, easy titling and overall performance of the PV tilting platform were declared as satisfactory.

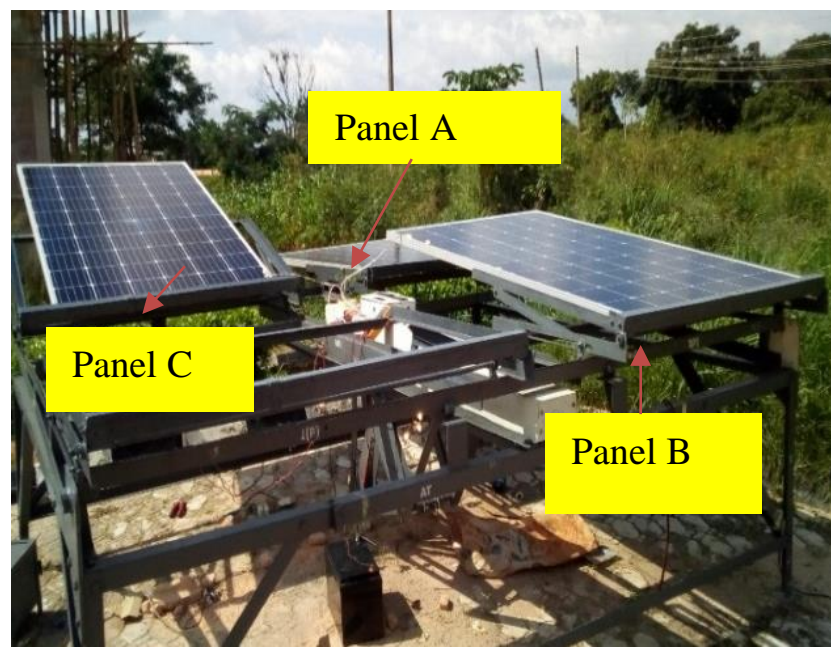

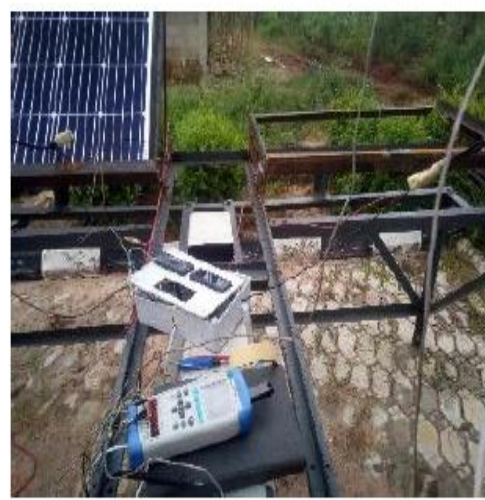

(a)

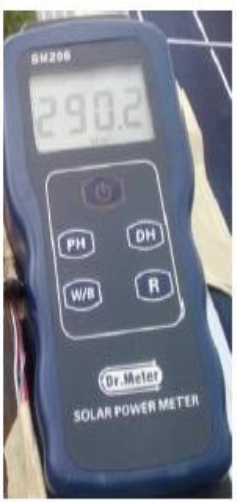

(b)

Figure 13. (a-b) Testing and Calibration of the prototype

Lastly, the three photovoltaic solar panels were installed at the prescribed angles; along with SM206 secondary standard irradiance meter and the AT4208 multi-channel temperature meter, for a period of 10 hours, in order to measure and record global horizontal irradiance and ambient temperature, as shown Fig. 13 (b). The experimental parametric datasets for temperature, humidity, solar irradiance, output current and output voltage of each of the three PV solar panels installed at different tilt-angles, were monitored, measured and recorded for every 20 seconds for the period of ten hours and thereafter, power output $(P)$ and the efficiency $(\eta)$ were calculated applying equation (21) and (22).

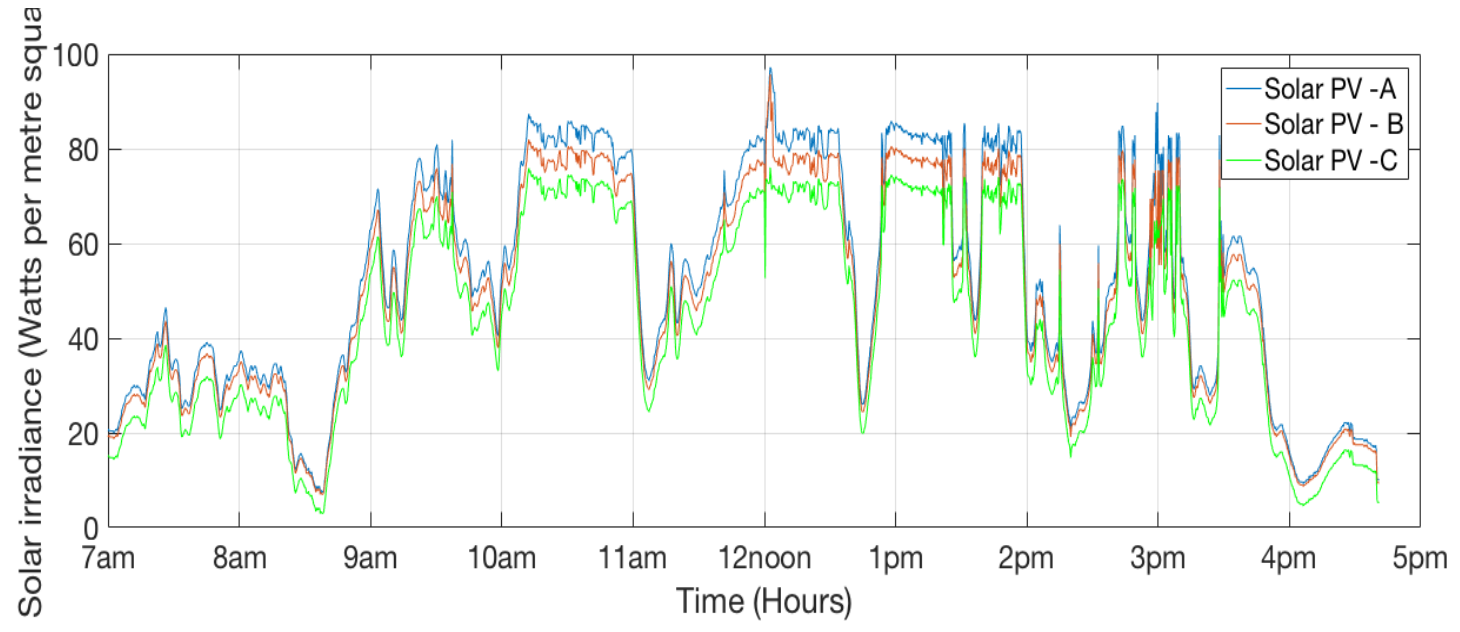

Figure 14. The charts of average irradiance

The charts of average irradiance and panel efficiency were plotted against time as shown in Fig. 14 and 15 respectively. Both charts indicated that irradiance and panel efficiency vary with the angle of tilt of the PV panel and also that the highest irradiance and panel efficiency were recorded between $12 \mathrm{~h} 00$ to $13 \mathrm{~h} 00$. Generally, in all of the three solar panels, an unstable output power efficiency harvest was observed. This could be associated with the uneven solar parameters, such as ambient temperature, solar irradiance and humidity, as indicated in Fig. 14 and 15. 


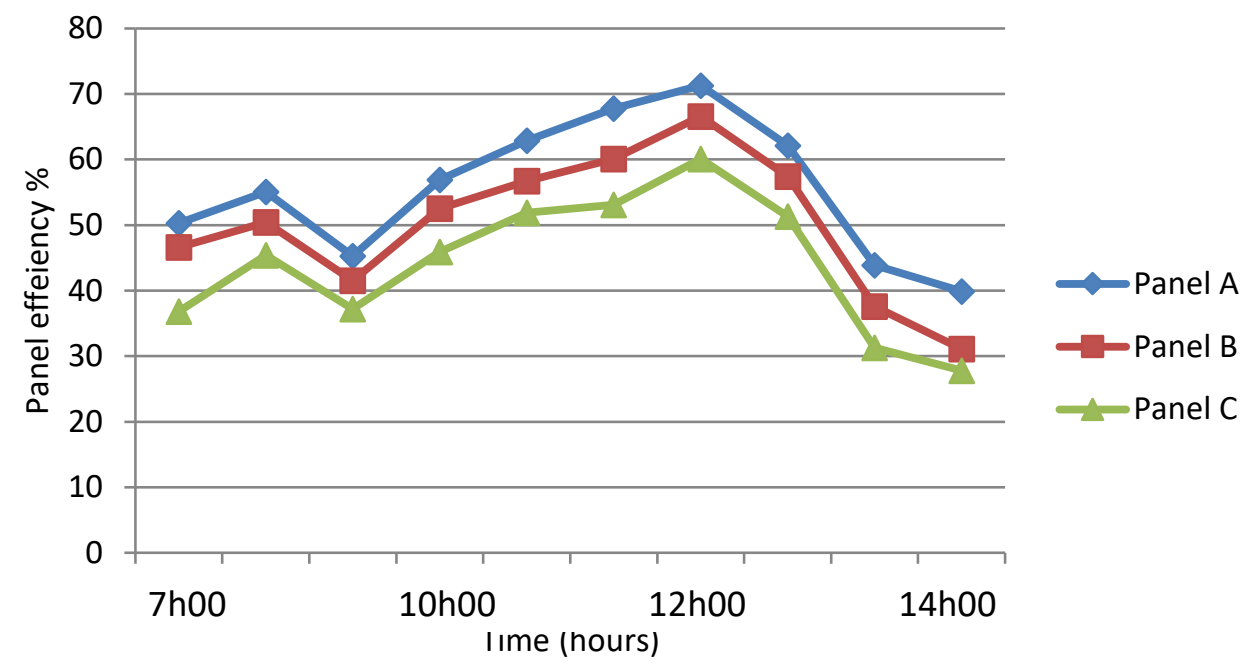

Figure 15: The charts of average panel efficiency

$$
\begin{gathered}
P=I * V \ldots \ldots \ldots \\
\eta=\frac{P}{\mathbf{2 5 0}} \times \mathbf{1 0 0} \%
\end{gathered}
$$

\section{Conclusion}

The numerous mechanisms of the PV tilting platform prototype were tested, the stability, strength, easy titling and overall performance of the PV tilting platform were declared as satisfactory. The optimum tilt-angle of a fixed photovoltaic solar panel is very important during the installation, in order to best exploit the accessible output power efficiency of the panel. The output power effectiveness of a PV solar collector is profoundly affected by its tilt-angle to the horizontal and its orientation. This is because of the detail that the sun's angle varies at every point of time and location. A photovoltaic solar panel installed at a fixed angle for a whole twelve months may be under-utilized. The optimum fixed tilt-angle is determined monthly; as the tilt-angles of the photovoltaic solar panels should be adjusted monthly or seasonally, in order to obtain the maximum output power efficiency from the photovoltaic solar panels.

\section{Declaration of competing interest}

The authors declare that they have no any known financial or non-financial competing interests in any material discussed in this paper.

\section{References}

[1] J.A. Duffie and W.A. Beckman, Solar engineering of thermal processes, John Wiley \& Sons, 2013.

[2] H.P. Garg, Treatise on solar energy: fundamentals of solar energy, vol. 1, 1982.

[3] P.J. Lunde, Solar thermal engineering: space heating and hot water systems, 1980.

[4] G.GadhaviAkash and D. Kundaliya. "Design and analysis of solar panel support structure-a review Paper." Int J Adv Res Eng Sci Technol 2, 2015.

[5] M.M. El-Kassaby, "Monthly and daily optimum tilt angles for south-facing solar collectors; theoretical model, experimental and empirical correlations, Solar \& Wind Technology, vol. 5, pp. 589-596, 1988.

[6] Y. Chang, Optimal the tilt angles for photovoltaic modules in Taiwan, International Journal of Electrical Power \& Energy Systems, vol. 32, pp. 956-964, 2010.

[7] M. Benghanem, Optimization of tilt angle for solar panel: Case study for Madinah, Saudi Arabia, Appl. Energy, vol. 88, no. 4, pp. 1427-1433, 2011. 
[8] D. Banks, The role of corner vortices in dictating peak wind loads on tilted flat solar panels mounted on large, flat roofs. Journal of Wind Engineering and Industrial Aerodynamics, 123, pp. 192-201, 2013.

[9] T. Daim, P. R. Newman, H . Sughi, \& E. Bakhsh, Technology selection for solar power generation in the middle east: Case of Saudi Arabia. In Handbook of research on solar energy systems and technologies, IGI Global, pp. 480-505, 2013.

[10] Solar by empire. http://solarbyempire.com/why-solar/solar-options/116-pole-mounts: assessed June $\underline{2021}$

[11] J. R. Anderson, M. L. Castillo, M. E. Osley, S. R. Sinapi, \& C. A. Beckel, Design of residental solar power mounting system (doctoral dissertation, Worcester Polytechnic institute), 2012.

[12] D. Banks, The role of corner vortices in dictating peak wind loads on tilted flat solar panels mounted on large, flat roofs. Journal of Wind Engineering and Industrial erodynamics, 123, 192-201, 2013.

[13] Omni calculator. https://www.omnicalculator.com/physics/air-density: assessed by July 2021. 